\title{
AVALIAÇÃO ROBUSTA DA MODELAGEM NEUTROSFÉRICA SOBRE O TERRITÓRIO BRASILEIRO BASEADA EM MODELOS DE PREVISÃO NUMÉRICA DE TEMPO DA AMÉRICA DO SUL
}

Robust evaluation of neutrospheric modeling over brasilian territory based on numerical weather prediction models of South American

TAYNÁ APARECIDA FERREIRA GOUVEIA ${ }^{1}$

LUIZ FERNANDO SAPUCCI ${ }^{1,2}$

JOÃO FRANCISCO GALERA MONICO ${ }^{1}$

DANIELE BARROCA MARRA ALVES ${ }^{1}$

${ }^{1}$ Universidade Estadual Paulista - UNESP

Programa de Pós-Graduação em Ciências Cartográficas

CEP 19.060-900 - Presidente Prudente - SP - Brasil

${ }^{2}$ Instituto Nacional de Pesquisas Espaciais, CPTEC

CEP 12.227-010 - Cachoeira Paulista - SP - Brasil

tayna.ppgcc@gmail.com; luiz.sapucci@cptec.inpe.br;

\{galera;danibarroca\}@fct.unesp.br.

\begin{abstract}
RESUMO
O posicionamento com o sistema GNSS (Global Navigation Satellite System) é atualmente a técnica mais utilizada para se obter a localização sobre a superfície terrestre ou próxima a essa. Depois dos efeitos causados pela ionosfera, a refração que o sinal sofre ao ultrapassar a neutrosfera pode ser considerada como uma das maiores fontes de erro no sinal, a qual gera um atraso, que rebatida na direção zenital é denominado atraso zenital neutrosférico (ZND), ou ainda atraso zenital troposférico (ZTD - Zenithal Tropospheric Delay). Esse atraso gera erros no posicionamento GNSS quando o mesmo não é devidamente modelado. Os modelos de Previsão Numérica de Tempo (PNT) são boas alternativas para a modelagem do ZND, pois como são alimentados diariamente por observações da atmosfera, os mesmos, geram previsões do ZND capazes de captar suas oscilações espaciais e temporais. No CPTEC/INPE são desenvolvidos e operacionalizados modelos de
\end{abstract}


PNT globais e regionais, sendo os últimos dedicados ao melhor detalhamento sobre a América do Sul. No Brasil está operacional no CPTEC/INPE um processo que gera tais previsões com resolução espacial de $15 \mathrm{~km}$ e temporal de 3 horas, além de outras versões que contemplam outras sofisticações. Para determinar o impacto dessas melhorias na qualidade das previsões do ZND, o presente trabalho apresenta uma avaliação robusta das versões disponibilizadas, utilizando como referência os valores de ZND estimados a partir dos dados GNSS coletados pelas estações da RBMC (Rede Brasileira de Monitoramento Contínuo), levando em consideração: a variação sazonal, a continentalidade e a variação da altitude e latitude.

Palavras-chave: Posicionamento GNSS; Atraso Zenital Neutrosférico; Previsão Numérica de Tempo; Assimilação de dados.

\section{ABSTRACT}

GNSS (GNSS - Global Navigation Satellite System) positioning is the most by used technique to obtain a location over terrestrial surface or close to it. After the effects generated by the ionosphere, the refraction that the signal suffers, when it goes through the neutrosphere, can be considered as one of the largest error sources in the signal, in which is generated a neutrospheric delay, also called Zenithal Tropospheric Delay (ZTD). When the ZTD is not modeled, significant errors in the GNSS positioning are observed. Numerical Weather Prediction models are good alternatives to obtain ZTD over South America, because they are fed daily by atmospheric observations and consequently they are able to capture the temporal and spatial oscillations of the ZTD values. In Brazil, a system is operating at CPTEC/INPE for the purpose of generating such forecasts with spatial resolution of $15 \mathrm{~km}$ and temporal of 3 hours. In order to assess the impact of the recent improvements in the quality of ZTD predictions, a robust evaluation of the ZTD predictions was performed, taking into consideration several analyses in the Brazilian territory, in which ZTD values obtained from GPS data collected by the RBMC stations were used as reference, considering the evaluation: seasonal, the continentality, altitude and latitude variation.

Keywords: GNSS Positioning; Zenith Neutrospheric Delay; Numerical Weather Prediction; Data Assimilation.

\section{INTRODUÇÃO}

O método de posicionamento baseado na utilização de satélites artificiais para a localização de um ponto sobre a superfície terrestre é o mais utilizado atualmente, devido aos seus aspectos práticos e a boa acurácia alcançada. A posição é obtida a partir do processamento de suas observáveis, a pseudodistância e a fase da onda portadora (SEEBER, 2003). De acordo com o nível de acurácia requerida na posição, diferentes métodos e equipamentos devem ser utilizados.

A propagação do sinal dos satélites GNSS está sujeita a diferentes fatores que implicam em erros no posicionamento, ocasionando assim a deterioração na 
acurácia da localização. Para uma melhor qualidade dessa localização esses erros devem ser minimizados ou eliminados. Tratando-se dos efeitos que o sinal sofre ao se propagar pela atmosfera terrestre, podem ser citados os causados pela influência da ionosfera e da neutrosfera, que atualmente, representam as maiores fontes de erros nas observáveis GNSS.

Com a minimização dos efeitos causados pela ionosfera, utilizando a observável ion-free, a refração que o sinal sofre ao ultrapassar a neutrosfera pode ser considerada a maior fonte de erro no sinal GNSS. Dessa forma, é essencial que tal efeito seja adequadamente tratado no posicionamento. Os efeitos que a neutrosfera causa no sinal GNSS são dados pelas diferentes variações dos elementos que compõem essa camada, sendo eles: cintilação neutrosférica, atenuação neutrosférica e o atraso neutrosférico (SPILKER et al., 1994).

A modelagem do atraso neutrosférico envolve duas fases. A primeira se concentra na determinação do atraso gerado no sinal do satélite ao se propagar através da neutrosfera, direção zenital (ZND), a partir das medidas de temperatura, pressão e umidade do perfil vertical neutrosférico. A segunda fase relaciona o ZND com o ângulo de elevação do satélite observado por meio das funções de mapeamento.

O atraso neutrosférico na direção zenital pode ser estimado como parâmetro adicional no posicionamento ou modelado através de equações matemáticas, ou seja, modelos empíricos. Os principais modelos empíricos que tratam do ZND são o de Hopfield e o de Saastamoinen (SEEBER, 2003). Como esses modelos são obtidos em função de valores de temperatura, pressão e umidade que consideram uma atmosfera padrão, não se apresentam totalmente apropriados para responder adequadamente as variações temporais e espaciais que ocorrem na América do Sul. Isto pode vir a ser um problema em alguns períodos quando se busca resultados acurados. Deve-se considerar ainda que nessa região encontra-se a vasta floresta Amazônica que exerce influência no clima global e regional, o que torna essa região única. Assim, para aplicações em tempo real que requerem alta acurácia, os modelos de Previsão Numérica de Tempo (PNT) podem ser uma boa alternativa para amenizar as limitações dos modelos teóricos para a América do Sul.

Desde meados de 2004 o Centro de Previsão de Tempo e Estudos Climáticos (CPTEC) do Instituto Nacional de Pesquisas Espaciais (INPE) gera operacionalmente previsões dos valores do ZND para toda a América do Sul e oceanos adjacentes, com o intuito de disponibilizar a comunidade geodésica uma alternativa, para minimizar os efeitos da neutrosfera nos sinais de radiofrequência para aplicações em tempo real. O ponto principal que norteia a disponibilização de versões do ZND é a disponibilidade operacional dos produtos de PNT no CPTEC. A versão inicial tinha resolução horizontal de $100 \mathrm{~km}$ (modelo GLB $100 \mathrm{~km}$ ) e 18 níveis na vertical (SAPUCCI et al., 2006). Em 2008 um novo modelo de previsão foi colocado operacional no CPTEC. Trata-se do modelo Eta com resolução espacial de $20 \mathrm{~km}, 19$ níveis verticais e previsões a cada 6 horas, o qual passou a ser utilizado nas previsões do ZND. Esse modelo apresentou melhorias na resolução 
horizontal e previsões mais representativas quanto às oscilações espaciais em relação à versão anterior (SAPUCCI et al., 2008). A partir de 2012 ficou operacional a nova versão da modelagem do ZND que utiliza o modelo Eta com resolução horizontal de $15 \mathrm{~km}$. Essa nova versão apresenta melhorias quanto à resolução espacial (horizontal e vertical) e temporal (de $6 \mathrm{~h}$ para $3 \mathrm{~h}$ ). O modelo Eta15 é o modelo atualmente operacional e essa é a versão utilizada nas previsões do ZND, que podem ser obtidas no endereço: http://satelite.cptec.inpe.br/zenital.

Além da resolução, outra melhoria que pode gerar aumento da qualidade nas previsões do ZND é a assimilação de dados. Com a assimilação é possível obter previsões mais próximas da realidade física da atmosfera, utilizando, para isso, campos de previsão de curto prazo e os mais diversos tipos de observações da atmosfera. Esse procedimento pode ser mais representativo, uma vez que utiliza dados regionais, levando em consideração as incertezas do modelo e a precisão das observações. Assim, adicionalmente as versões operacionais, nesse trabalho é realizada uma avaliação inicial do impacto da assimilação de dados, e para isso foi utilizado o sistema de assimilação regional RPSAS (Regional Physical-space Statistical Analysis System) com resolução temporal de 6 horas e espacial de 40 km, que esteve operacional até fevereiro de 2012.

Alguns trabalhos apresentam o impacto da utilização da modelagem neutrosférica no posicionamento GNSS. Em Dalbelo et al.(2006), os resultados mostraram que as melhorias com o uso das previsões do ZND com modelagem PNT chegaram até $16,6 \%$ (estação VARG) em relação ao modelo teórico de Hopfield, na correção do atraso neutrosférico no posicionamento DGPS (Differential Global Positioning System), porém nessa avaliação foram utilizadas apenas quatro estações processadas em quatro dias com 21 horas cada. Em Oliveira (2013) foram realizados testes com dados em cada estação do ano (primavera, verão, outono e inverno) utilizando o modelo do ZND com PNT e o modelo de Hopfield avaliando a qualidade de ambos, mas nessa análise foram selecionadas cinco estações do estado de São Paulo e 45 dias. O modelo que utiliza PNT apresentou melhor desempenho principalmente nos dias mais úmidos. Embora essas avaliações apresentem maior qualidade das previsões do ZND em relação ao modelo teórico de Hopfield, essas avaliações não foram desenvolvidas para longos períodos, assim como em região de grande abrangência, de tal forma que proporcionasse uma avaliação mais robusta. Desta forma, esse artigo tem como objetivo apresentar a avaliação da modelagem da neutrosfera para a América do Sul obtida com as versões melhoradas com relação à resolução e a assimilação de dados nos modelos de PNT disponíveis no CPTEC. É realizada uma avaliação robusta das previsões do ZND considerando períodos longos de dados e estações do ano em todo território brasileiro, utilizando dados da RBMC. Foram também realizadas análises onde se considera os impactos da variação sazonal, da continentalidade, e variações de altitude e latitude das estações.

Para avaliar os resultados da previsão do ZND advindos dos diferentes modelos disponíveis, foi realizada a comparação do atraso obtido via modelo de PNT (ZND previsto) e as estimativas do ZND via processamento de dados GNSS 
utilizando o software GOA-II (GIPSY - GNSS Inferred Positioning System; OASIS Orbit Analysisand Simulation Software II) (GREGORIUS, 1996), considerados valores de referência devido a sua alta qualidade e confiabilidade (SAPUCCI, 2005).

Esse artigo está organizado em cinco seções. Na seção 2 são descritos os modelos de PNT considerados no trabalho e a metodologia utilizada na modelagem do atraso neutrosférico. Na seção 3 são apresentados os dados disponíveis e o software utilizado, bem como a metodologia de avaliação. Os resultados e análises dos mesmos são apresentados na seção 4, enquanto na seção 5 são discutidas as considerações finais e conclusões.

\section{MODELAGEM NEUTROSFÉRICA USANDO MODELOS DE PNT}

A atmosfera terrestre pode ter divisões e denominações diferentes nas diferentes áreas de pesquisa, nas quais são divididas de acordo com a temperatura, ionização, propagação do sinal e altitude. Na Geodésia, a divisão das camadas se dá pela quantidade de elétrons que as compõem. Assim, a atmosfera é dividida em ionosfera e neutrosfera.

A ionosfera é a camada com espessura que vai de 50 a 1000 quilômetros, e é composta por elétrons livres, que afetam a propagação de ondas eletromagnéticas quanto à velocidade e sua direção. No sinal GNSS, o efeito de $1^{a}$ ordem da ionosfera (responsável por aproximadamente $99 \%$ do efeito total) é proporcional ao conteúdo total de elétrons (TEC - Total Electron Content) (CAMARGO, 1999). Por ser um meio dispersivo, a influência da ionosfera é dependente da frequência do sinal e, dessa maneira, com o uso de observáveis obtidas por dupla frequência, é possível minimizar esse erro a partir de uma combinação linear adequada.

A neutrosfera é a camada da atmosfera eletricamente neutra e composta por uma alta concentração de gases como o nitrogênio, oxigênio, dióxido de carbono, argônio e vapor d'água. Ela se estende, em média, até $50 \mathrm{~km}$, indo da superfície terrestre até o início da ionosfera. Em relação à atmosfera na Meteorologia, essa camada se estende desde o nível do mar até parte da estratopausa, contendo a troposfera (até $12 \mathrm{~km}$ próximo ao equador), tropopausa e estratosfera. Devido àneutrosfera ser composta por gases secos e vapor d'água, essa pode ser dividida em duas componentes: seca (dry) e úmida (wet). A componente seca também denominada hidrostática é formada por $78 \%$ de nitrogênio, $21 \%$ de oxigênio e outros gases em pequenas proporções. Já a componente úmida, é composta pelo vapor d'água (SEEBER, 2003). O atraso neutrosférico total se dá pela soma dessas duas componentes e este gera erros na direção satélite-receptor com dimensões significativas podendo chegar até 25 metros próximo ao horizonte. Por essa razão deve ser tratado de forma adequada.

\subsection{Atraso Neutrosférico}

O sinal GNSS ao se propagar na neutrosfera sofre mudança de velocidade e de direção, por atravessar dois meios (camadas) com composições diferentes, o que 
ocorre devido à refratividade, ocasionando um atraso no sinal denominado atraso neutrosférico, o qual é independente da frequência do sinal dos satélites, em consequência da neutrosfera ser eletricamente neutra. Dessa forma o atraso neutrosférico depende apenas das características termodinâmicas da atmosfera.

As duas componentes nas quais a neutrosfera pode ser divida são: a componente seca composta de gases secos, responsável pelo chamado atraso hidrostático (HD- Hydrostatic Delay) que representa $90 \%$ do atraso total e possui baixa variação temporal; e outra componente composta de vapor d'água, responsável pelo atraso úmido (WD - Wet Delay) que corresponde a 10\% do atraso total, porém sua variação pode atingir cerca de $20 \%$ em poucas horas (SEEBER, 2003). Isso se deve à variação do vapor d'água ao longo de poucas horas do dia. A melhor predição do WD pode ser obtida através de perfis de umidade e temperatura. A soma das duas componentes na direção zenital (ZHD - Zenital Hidrostatic Delay - Atraso Zenital Hidrostático, e ZWD - Zenital Wet Delay - Atraso Zenital Úmido) resulta no ZND, com ordem de grandeza de aproximadamente $2,5 \mathrm{~m}$, podendo atingir cerca de 10 vezes maior no horizonte. Em Spilker et al.(1994) são apresentadas as equações que representam as componentes do ZND.

Para analisar o ZND é necessário investigar o comportamento da refratividade atmosférica em relação à variação da altitude dentro do intervalo da altura efetiva dessa camada atmosférica (SAPUCCI, 2001). Note que os valores de um perfil vertical são mais representativos que os medidos em superfície, pois esses parâmetros são muito variáveis ao longo da atmosfera. Esses valores podem ser obtidos pelo radiômetro, equipamento com o qual é possível obter estimativas da refratividade que são geradas pela componente úmida, ou a partir de dados de radiossondas, equipamento que possui sensores que são transportados por balões meteorológicos. Esses sensores medem diversos parâmetros atmosféricos e os transferem via sinal de rádio a uma estação fixa. As radiossondas são lançadas, em geral, as $00 \mathrm{~h}$ e $12 \mathrm{hUTC}$, atingindo até $25 \mathrm{~km}$ de altura. Elas possibilitam a integração numérica na coluna vertical sobre a estação utilizando os valores de pressão $(e)$ e temperatura $(T)$ ambos em função da pressão atmosférica. Embora esses métodos convencionais, como os radiômetros e as radiossondas, fornecem esses valores com alta precisão, eles são de alto custo, o que restringe o número de lançamentos diários das radiossondas e o número de estações, equipadas com radiômetros (BEVIS et al., 1992). Em face do exposto, os modelos de PNT são uma boa alternativa para a modelagem do ZND.

\subsubsection{Previsões do ZND com PNT}

A PNT tem como princípio básico a obtenção do estado futuro da atmosfera em um determinado instante a partir de um estado inicial. Tal processo é chamado de análise, que é obtido pelo processo de assimilação de dados, com o uso das observações, utilizando-se de um modelo físico da atmosfera que possa ser integrado numericamente no tempo. O melhor resultado na previsão está relacionado com a capacidade de modelar com mais eficiência a atmosfera terrestre, 
e com qualidade seu estado inicial (SAPUCCI, 2007). Porém, um erro na análise do estado inicial pode ser propagado e causar maiores erros no estado previsto. Dessa forma, se faz necessário o maior número possível de dados das variáveis atmosféricas no início do processo. Além disso, é necessária a utilização de um controle de qualidade robusto para selecionar adequadamente esses dados. Isto pode ser obtido com a assimilação de dados, uma vez que esse processo utiliza campos de previsão de curto prazo e os mais diversos tipos de observações da atmosfera (ANDREOLI et al., 2008), levando em consideração as incertezas do modelo e a precisão das observações. O processo de assimilação de dados em um modelo de PNT é um procedimento cíclico onde os resultados gerados pelo modelo de PNT com integração curta (FG - First Guess) são combinados com os valores observados em um ajustamento de observações. Visando obter melhores previsões de tempo, modelos com melhores resoluções horizontais, verticais e temporais são desenvolvidos, assim como a utilização da assimilação de dados regionais.

Em Sapucci et al.(2004) é apresentada a modelagem do ZND com o uso da PNT, onde são apresentadas as equações e processos utilizados. É comum a utilização de duas etapas para a modelagem do atraso neutrosférico. Na primeira, a determinação do atraso na direção zenital, usando os valores de pressão, temperatura e umidade ao longo da coluna vertical ou uma modelagem baseada nesses dados. Já a segunda etapa é o de relacionar o atraso na direção zenital com o ângulo de elevação e azimute do satélite observado, através da função de mapeamento.

Até 2012 esteve operacional no CPTEC/INPE um sistema de assimilação de dados da América Latina, o RPSAS (Regional Physical-space Statistical Analysis System). Herdies et al. (2008) realizaram uma avaliação entre o modelo Eta que utiliza análise do centro americano NCEP (National Centers for Environmental Prediction) e o sistema RPSAS. Esse último apresentou melhores resultados nas previsões a partir de 48 horas, como também não apresentou queda de qualidade nas primeiras 24 horas de previsão.

Na seleção dos modelos para esse artigo procurou-se considerar dois aspectos importantes: a melhor resolução temporal e espacial, e a possível contribuição da assimilação de dados (CPTEC/INPE). Na seleção dos modelos foi levada em consideração à disponibilidade e acessibilidade dos arquivos para o maior período possível. Os modelos a serem considerados são apresentados na Tabela 1.

Tabela 1 - Características dos modelos utilizados na avaliação.

\begin{tabular}{c|c|c|c|c}
\hline Modelos & Res.Esp. & Res. Temp. & Assimilação Reg. & Operacional \\
\hline Eta $20 \mathrm{~km}$ & $20 \times 20 \mathrm{~km}$ & 6 horas & Não & Até Fev/2012 \\
\hline Eta $15 \mathrm{~km}$ & $15 \times 15 \mathrm{~km}$ & 3 horas & Não & Até Fev/2012 \\
\hline RPSAS & $40 \times 40 \mathrm{~km}$ & 6 horas & Sim & Fev/2012 \\
\hline
\end{tabular}


- O modelo Eta $20 \mathrm{~km}$ foi escolhido, porque até a data mencionada era utilizado na modelagem do ZND operacional disponível no CPTEC;

- O modelo Eta $15 \mathrm{~km}$, que em relação ao de $20 \mathrm{~km}$ apresenta um detalhamento maior sobre a região da América do Sul. Um ponto forte dessa versão é a resolução temporal;

- O modelo RPSAS como possui integrado o processo de assimilação de dados regional, espera-se que apresente melhores estimativas do ZND nas primeiras horas de previsão;

O ZND é obtido utilizando dados dos modelos de PNT operacionais no CPTEC/INPE, sendo eles valores previstos de temperatura, pressão e umidade nos diferentes níveis disponibilizados, de acordo com cada modelo, as 00h e 12h UTC. O ZWD e ZHD sãoobtidos nos mesmos intervalos de tempo e na mesma grade em que os modelos numéricos geram suas previsões. A soma dessas duas componentes têm-se o ZND. Com esses valores nos pontos da grade dos modelos utilizados, esses podem por interpolação ser determinados para qualquer ponto pertencente ao domínio espacial de cada modelo de PNT.

\section{METODOLOGIA DE AVALIAÇÃO DAS PREVISÕES DO ZND}

A metodologia empregada na implementação de novas versões das previsões do atraso neutrosférico se dá através da adaptação das versões já desenvolvidas anteriormente no CPTEC para os novos formatos de arquivos com novas resoluções e assimilação de dados.

Para a modelagem do ZND com dados de PNT foram utilizados programas em linguagem FORTRAN, disponíveis em sistema operacional LINUX, que proporcionam os cálculos para a modelagem do ZND, bem como do aplicativo GRADS (Grid Analysis and Display System), ferramenta que proporciona a geração das grades que formam os arquivos binários e imagens, com adaptações quanto à resolução temporal e espacial para o processamento dos dados. Para uma avaliação adequada dos resultados obtidos com os diferentes modelos, as estimativas do ZND obtidas com o processamento dos dados GNSS no GOA-II (mais detalhes no item 3.2) são tomadas como referência e em diferentes aspectos os mesmos modelos são avaliados. Detalhes da metodologia de avaliação, descrição dos dados e do processamento dos dados GNSS são apresentados nas seções 3.1, 3.2, 3.3.

\subsection{Dados Utilizados na Avaliação}

Os dados utilizados na geração do ZND para as avaliações advêm apenas da tecnologia GPS, haja vista que a versão do software GOA-II era restrita a esse sistema. Devido à disponibilidade dos modelos de PNT se darem em diferentes períodos, os modelos Eta20km e RPSAS são avaliados no período que compreende os anos de 2010 e 2011 no que consta uma avaliação robusta, enquanto que o modelo Eta15 é avaliado em 2012. Os três modelos foram concomitantes apenas em fevereiro de 2012, quando o Eta20 e RPSAS estavam em processo de desativação. 
Na avaliação robusta dos resultados foram utilizadas 77 estações da RBMC (Figura 1), nos anos de 2010, 2011 e 2012. O modelo operacional Eta15 foi utilizado nas avaliações sazonais no período de janeiro, fevereiro e julho, continentalidade, latitude e altitude, em fevereiro de 2012. A análise dos resultados, para as diferentes avaliações foi realizada considerando diversos aspectos espaciais e temporais. Na Figura 1 e Tabela 2 são apresentadas as estações selecionadas e suas respectivas regiões.

Características das diferentes avaliações:

- Sazonal - considerando que sazonalidade são as oscilações anuais do comportamento da atmosfera em relação às estações do ano que impactam significativamente no clima de forma mais ou menos intensa, dependente da localização das estações. Sendo que em regiões próximas ao Equador há pouca variação devido à incidência e refração do Sol quase que constante ao longo do ano. Já em regiões subtropicais, a incidência do Sol é maior em uma época que em outra (maior no verão e menor no inverno). Dessa forma, essas variações impactam na qualidade das previsões do ZND mais em um período que em outro, em função direta com a latitude do local. Assim nessa análise pretende-se avaliar o desempenho das previsões do ZND nas diferentes estações do ano, e identificar onde esse desempenho é bom e onde não é significativo. As estações foram selecionadas seguindo um critério em que as localizações foram levadas em consideração, na qual estações de menores latitudes (próximas ao Equador) até estações de latitudes maiores (próximas e ao sul do Trópico de Capricórnio). Essas estações estão localizadas na região continental do Brasil, visando isolar a influência das características costeiras, sendo elas: NAUS, BRAZ, UBER, SJRP, PPTE, UFPR, PRGU e SMAR (destacadas na Figura 1 em círculos verdes), no ano de 2012 os meses de janeiro e fevereiro visando caracterizar o verão, e junho e julho caracterizando o inverno;

- Continentalidade - nessa análise pretende-se verificar o desempenho do modelo nas estações que se encontram em regiões litorâneas, comparadas com estações localizadas no interior do continente, no período de fevereiro de 2012. A escolha de pares de estações foi feita tentando isolar outras variáveis que pudessem interferir nessa análise. Os pares de estações selecionadas foram CEEU-NAUS, RIOD-PPTE e POAL-SMAR (destacadas em círculos azuis);

- Latitude - Nessa análise pretende-se avaliar o desempenho das previsões do ZND em estações de diferentes latitudes mais que não fossem influenciadas pela continentalidade ou variação da altitude, em fevereiro de 2012. Para isso foram selecionadas as estações na costa, para não serem afetadas pelo impacto da altitude nessa análise. De acordo com esse critério foram empregadas as estações: CEEU, ALAR, SAVO, RIOD, NEIA, IMBT e POAL (em destaque na Figura 1 com círculos vermelhos);

- Altitude - nessa análise objetiva-se avaliar o impacto da altitude no desempenho dos modelos de PNT nas previsões do ZND, mantido os valores 
das latitudes em três diferentes regiões onde se observa uma variação significativa da altitude. $\mathrm{O}$ objetivo é tentar minimizar o impacto da variação latitudinal e avaliar apenas o impacto da variação da altitude nas diferentes regiões. A região da estação $\mathrm{BRAZ}$ (lat $\cong-16^{\circ}$ ), região da estação PPTE (lat $\cong-$ $22^{\circ}$ ) e região da estação UFPR (lat $\cong-25^{\circ}$ ) no período de fevereiro de 2012 . As estações selecionadas para avaliar o impacto da altitude foram: CUIB $(237,44 \mathrm{~m})$, ROSA $(299,69 \mathrm{~m})$, MTBA $(322,83 \mathrm{~m})$, PPTE $(431,05 \mathrm{~m})$, PRMA $(543,37 \mathrm{~m})$, CHPI $(617,41 \mathrm{~m})$, RIOD $(8,63 \mathrm{~m})$, POLI $(730,62 \mathrm{~m})$, UFPR (925,81m), PRGU $(1043,1 \mathrm{~m})$ e BRAZ $(1106 \mathrm{~m})$ (em destaque na Figura 1 por círculos roxos).

Figura 1 - Localização das estações da RBMC.

Fonte: Adaptada de IBGE.

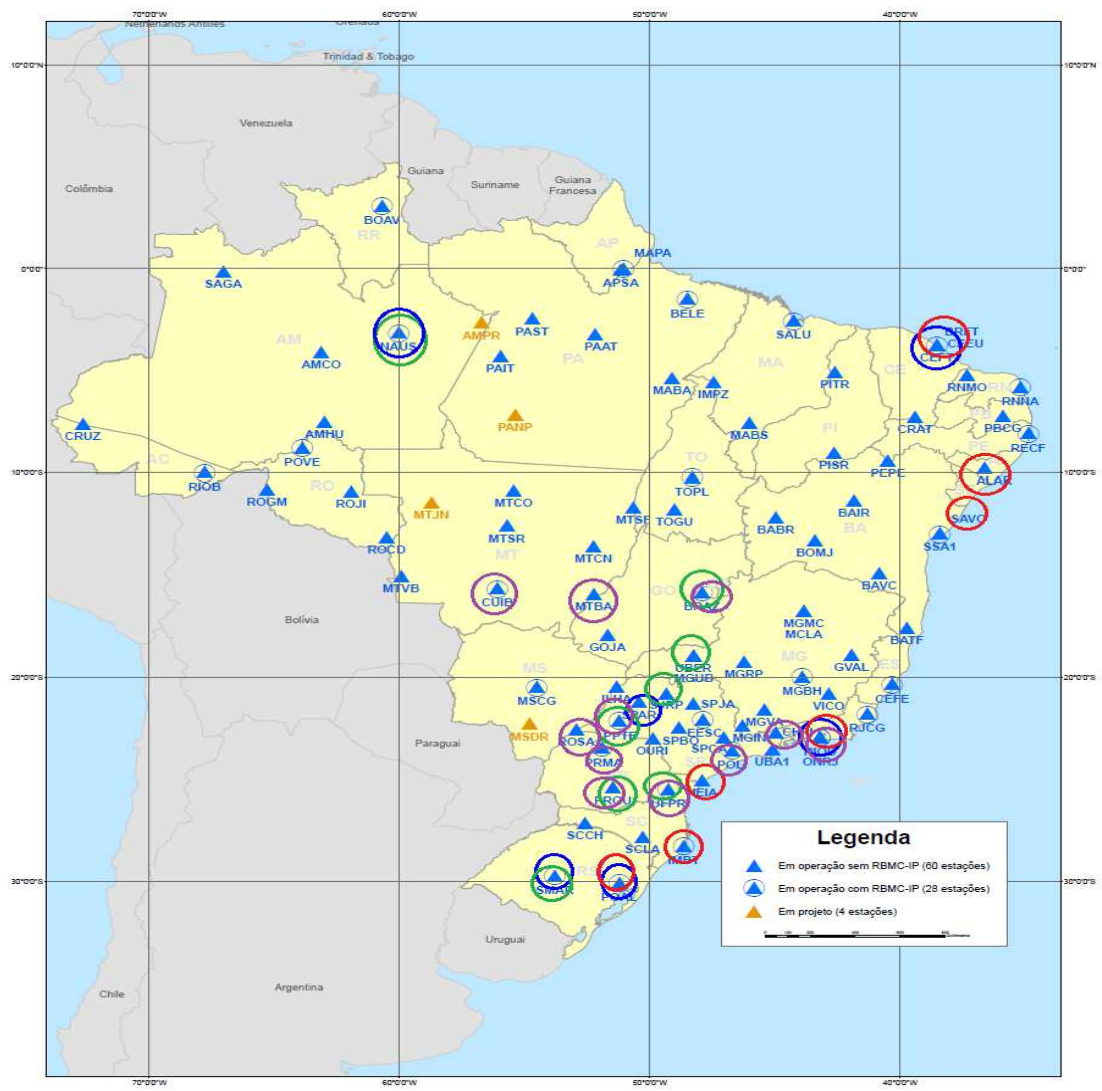

Bol. Ciênc. Geod., sec. Artigos, Curitiba, v. 20, nº 3, p.481-503, jul-set, 2014. 
Tabela 2 - Lista das características das estações utilizadas na avaliação.

\begin{tabular}{c|c|c|c|c}
\hline Sigla & Cidade - Estado & Latitude $\left(^{\circ}\right)$ & Longitude $\left(^{\circ}\right)$ & Altitude $(\mathrm{m})$ \\
\hline ALAR & Arapiraca - AL & $-9,75$ & $-36,65$ & 266,23 \\
\hline BRAZ & Brasília - DF & $-15,95$ & $-47,88$ & 1106,00 \\
\hline CEEU & Fortaleza - CE & $-3,88$ & $-38,43$ & 21,75 \\
\hline CHPI & Cachoeira Paulista - SP & $-22,69$ & $-44,99$ & 617,41 \\
\hline CRAT & Crato - CE & $-7,24$ & $-39,42$ & 436,05 \\
\hline CUIB & Cuiabá - MT & $-15,56$ & $-56,07$ & 237,44 \\
\hline IMBT & Imbituba - SC & $-28,23$ & $-48,66$ & 31,41 \\
\hline MTBA & Barra do Garça - MT & $-15,89$ & $-52,26$ & 322,83 \\
\hline NAUS & Manaus - AM & $-3,02$ & $-60,01$ & 93,89 \\
\hline NEIA & Cananéia - SP & $-25,02$ & $-47,92$ & 6,06 \\
\hline POAL & Porto Alegre - RS & $-30,07$ & $-51,12$ & 76,75 \\
\hline POLI & São Paulo - SP & $-23,56$ & $-46,08$ & 730,62 \\
\hline PPTE & Pres. Prudente - SP & $-22,12$ & $-51,41$ & 431,05 \\
\hline PRGU & Guarapuava - PR & $-25,38$ & $-51,49$ & 1043,10 \\
\hline PRMA & Maringá - PR & $-23,41$ & $-51,94$ & 543,37 \\
\hline RIOD & Rio de Janeiro - RJ & $-22,82$ & $-43,31$ & 8,63 \\
\hline ROSA & Rosana - SP & $-22,52$ & $-52,95$ & 299,69 \\
\hline SAVO & Salvador - BA & $-12,94$ & $-38,43$ & 76,32 \\
\hline SJRP & São José do Rio Preto - SP & $-20,79$ & $-49,36$ & 535,91 \\
\hline SMAR & Santa Maria - RS & $-29,72$ & $-53,72$ & 113,11 \\
\hline UBER & Uberlândia - MG & $-18,89$ & $-48,32$ & 791,83 \\
\hline UFPR & Curitiba - PR & $-25,45$ & $-49,23$ & 925,81 \\
\hline & & & &
\end{tabular}

\subsection{Metodologia de Avaliação dos Resultados com Estimativas Advindas do GOA-II}

O software GOA-II foi desenvolvido pelo JPL (Jet Propulsion Laboratory) e pode ser utilizado para processamento de dados de várias tecnologias, tais como GNSS, SLR (Satellite Laser Range) e DORIS (Doppler Orbitography and Radio Positioning Integrated by Satellite). Os dados de entrada GPS devem estar no formato RINEX (Receiver Indenpedent Exchange format). O GOA-II pode ser considerado como um dos programas que representa o estado da arte em processamentos de dados GNSS. Esse software permite realizar posicionamento por ponto de alta precisão (PPP), onde são utilizadas as duas observáveis disponíveis nas duas portadoras, bem como as efemérides precisas juntamente com as correções dos relógios dos satélites. Com os dados de dupla frequência é possível reduzir os efeitos da ionosfera a partir do uso de combinação linear apropriada (GREGORIUS, 1996). As estimativas do ZND são realizadas utilizando o GOA-II processando dados GPS no método PPP onde a componente úmida e os resíduos da hidrostática comparecem como parâmetro adicional nas equações. O ZND apresenta correlação 
temporal, estando uma época específica dependente da anterior. Dessa forma, é utilizado o método estocástico Random Walk que é caracterizado principalmente pelo aumento da incerteza dos parâmetros serem proporcional à raiz quadrada do intervalo de tempo entre as épocas de processamento (Blewitt, 1997). Em SAPUCCI (2005) é apresentada uma avaliação do ZND estimado com o GOA-II, em relação aos dados de radiossondas (valores medidos considerados próximos ao valor verdadeiro), onde é possível observar a qualidade dos valores estimados. Os valores obtidos via GPS apresentaram concordância com os gerados a partir de radiossondas, assegurando a qualidade dos mesmos, que se mostram adequados para avaliar a qualidade do ZND obtido através da PNT.

\subsection{Análises Estatísticas}

Para o desenvolvimento da metodologia de avaliação foram utilizadas rotinas em MATLAB (MATrix LABoratory) que calculam as seguintes métricas estatísticas: o viés (erro médio) que mostra a tendência do valor previsto em relação ao valor tomado como referência (ZND estimado); o desvio padrão que avalia a dispersão do valor previsto em relação ao valor médio de referência; e o Erro Médio Quadrático (RMS - Root Mean Square) que torna mais claro os resultados obtidos, apresentando a acurácia (MONICO et al., 2009) de tais resultados se considerado a referência como valor correto. Essas estatísticas são calculadas para a avaliação robusta, e avaliações quanto à variação sazonal, continentalidade, latitude e altitude, descritas na seção 3.1.

\section{RESULTADOS E ANÁLISES}

Os resultados aqui apresentados nos diferentes aspectos considerados serão em relação ao viés, ao EMQ e ao Desvio Padrão (DP), considerando as previsões da 00 hora UTC, as quais estão disponíveis ao usuário no máximo às 09 horas UTC. Na sequência os demais aspectos já descritos na seção anterior são abordados e os resultados apresentados e discutidos.

\subsection{Avaliação Robusta}

A avaliação das previsões do ZND a partir de cada modelo é apresentada nas figuras 2 e 3, sendo que na primeira apenas os modelos Eta20 e RPSAS são comparados em 2010 e 2011, e na segunda todos participam com dados gerados em fevereiro de 2012. Uma avaliação robusta baseada na Figura 2 indica que o Eta20 apresenta uma variação mais significativa durante o intervalo de 6 horas de integração dos modelos do que os demais modelos avaliados. Os resultados apresentados mostram que o EMQ do Eta20 é de 2,5 cm na condição inicial e depois de 6 horas de integração fica abaixo de $1 \mathrm{~cm}$ e permanece nesse patamar na avaliação de 2010. Já na avaliação de 2011 ele apresenta um comportamento contrário. Nesse caso apresenta EMQ abaixo de $1 \mathrm{~cm}$ nas primeiras horas de integração e de $2,5 \mathrm{~cm}$ entre 6 e 18 horas de integração e retorna para valores inferiores a $1 \mathrm{~cm}$ com 24 horas de integração. O RPSAS apresenta tanto em 2010 
como em 2011 um EMQ de 2,5 cm. Na análise dos valores do EMQ observa-se que a maior contribuição advém do DP, que expressa maior dispersão do ZND previsto em relação ao de referência. Já o viés tem uma influência menor, visto que em todos os modelos e períodos avaliados fica abaixo de $1 \mathrm{~cm}$, RPSAS com viés de $3 \mathrm{~mm}$, e o Eta20 apresenta viés nulo.

Figura 2 - Viés, Desvio Padrão e Erro Médio Quadrático $(\mathrm{em} \mathrm{cm})$ do ZND considerando 77 estações da RBMC para os meses de Jan/Fev/Abr/Jul/Out de 2010 e 2011 para os modelos Eta20, RPSAS.

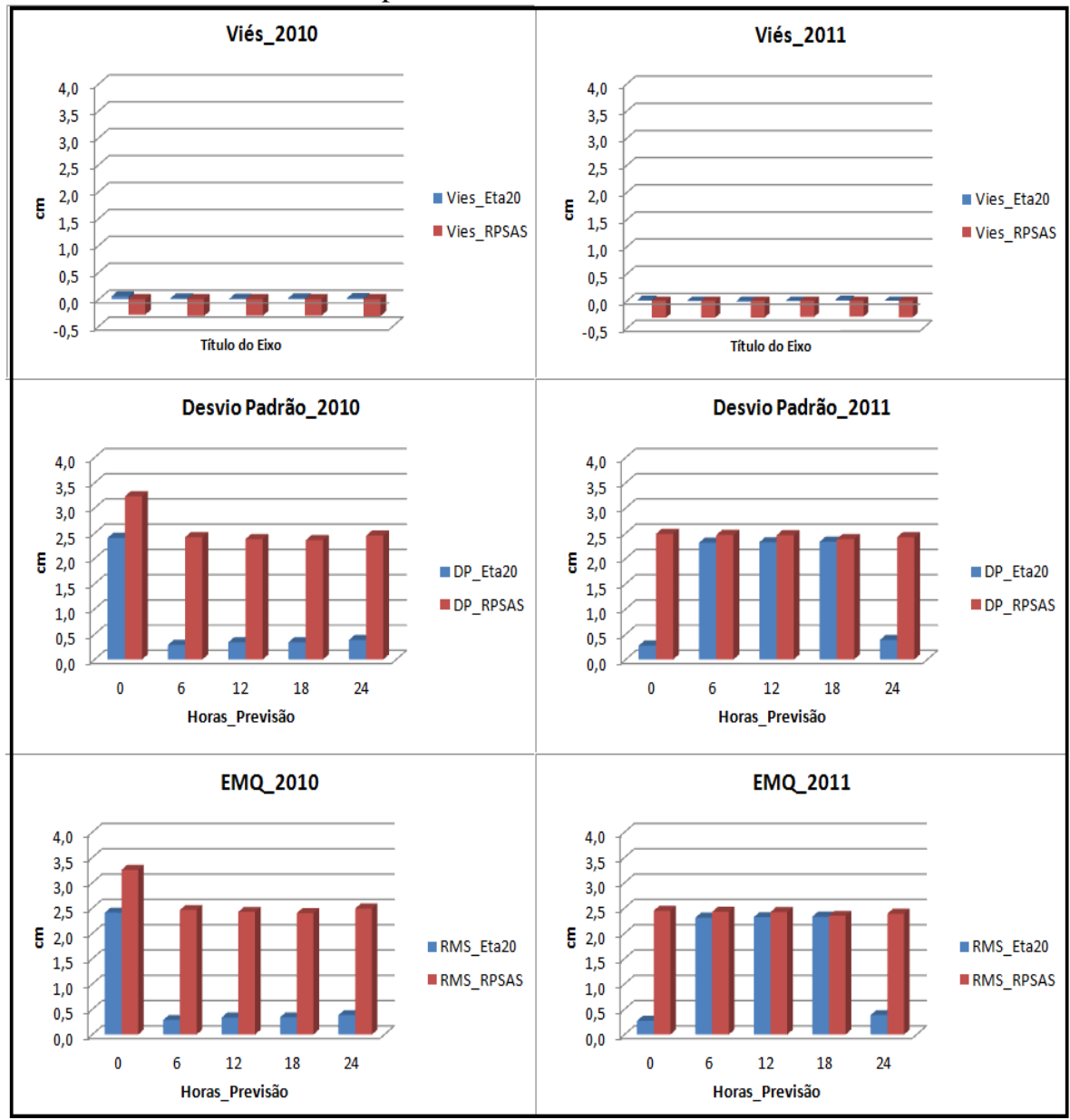

Bol. Ciênc. Geod., sec. Artigos, Curitiba, v. 20, nº 3, p.481-503, jul-set, 2014. 
Figura 3 - Viés, Desvio Padrão e Erro Médio Quadrático (em cm) do ZND considerando 77 estações no mês de Fevereiro de 2012 para os modelos Eta20,

RPSAS e Eta15.

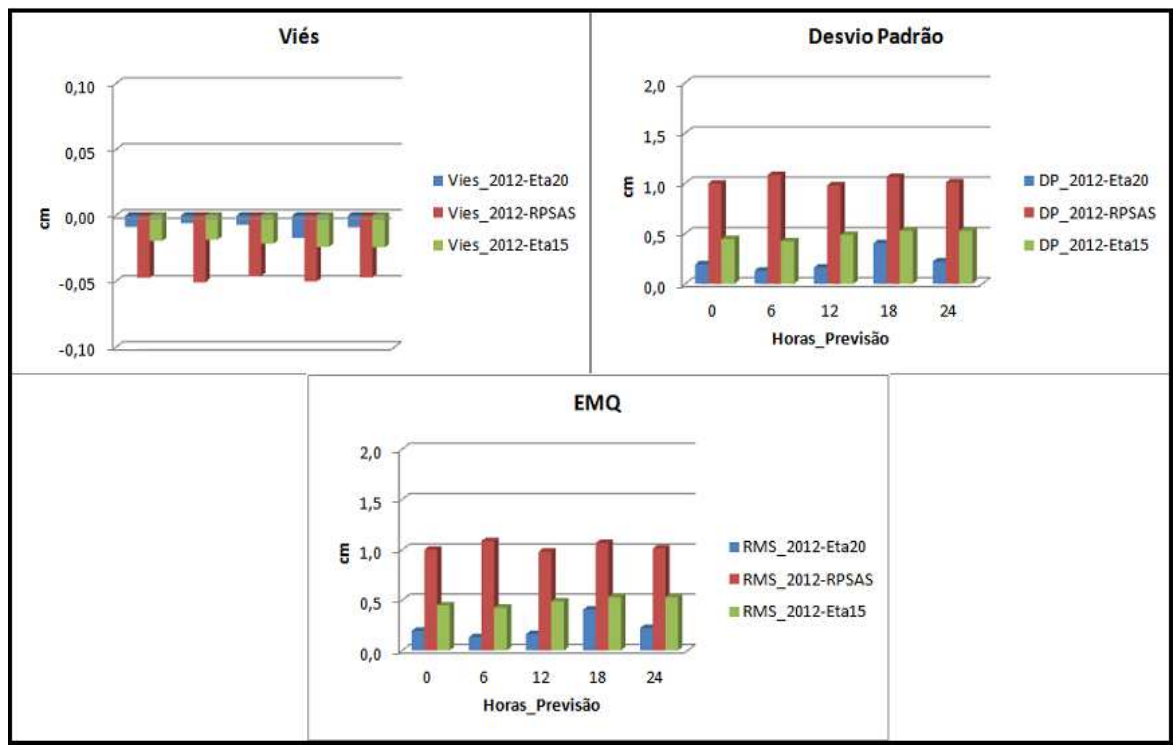

Tabela 3 - Viés, DP e EMQ (em mm) do ZND considerando 77 estações no mês de Fevereiro de 2012 para os modelos Eta20, RPSAS e Eta15.

\begin{tabular}{|c|c|c|c|c|c|c|}
\hline & $\begin{array}{l}\text { Horas de } \\
\text { Previsão }\end{array}$ & 00 & 06 & 12 & 18 & 24 \\
\hline \multirow{3}{*}{ VIES } & Eta20 & $-0,0$ & $-0,057$ & $-0,070$ & $-0,168$ & $-0,088$ \\
\hline & RPSAS & $-0,5$ & $-0,506$ & $-0,459$ & $-0,500$ & $-0,468$ \\
\hline & Eta15 & $-0,2$ & $-0,182$ & $-0,213$ & $-0,238$ & $-0,240$ \\
\hline \multirow{3}{*}{ DP } & Eta20 & 1,9 & 1,303 & 1,618 & 4,039 & 2,218 \\
\hline & RPSAS & 10,0 & 10,831 & 9,790 & 10,639 & 10,110 \\
\hline & Eta15 & 4,5 & 4,244 & 4,863 & 5,285 & 5,269 \\
\hline \multirow{3}{*}{ EMQ } & Eta20 & 1,9 & 1,305 & 1,621 & 4,045 & 2,221 \\
\hline & RPSAS & 10,0 & 10,852 & 9,809 & 10,659 & 10,129 \\
\hline & Eta15 & 4,5 & 4,250 & 4,871 & 5,294 & 5,278 \\
\hline
\end{tabular}

Como pode ser observado na Figura 3, em média o EMQ do modelo Eta20 se apresenta em torno de 0,2 cm e do modelo Eta15 EMQ de 0,4 cm, o maior impacto no EMQ se dá em relação ao DP, os valores numéricos são apresentados na Tabela 3 , para melhor visualização. O modelo RPSAS apresenta estabilidade na qualidade das previsões, embora apresente uma subestimação no viés de $-0,05 \mathrm{~cm}$. O Eta20 apresenta $0,01 \mathrm{~cm}$ (também subestima) variando em até $0,02 \mathrm{~cm}$. O Eta15 apresenta

Bol. Ciênc. Geod., sec. Artigos, Curitiba, v. 20, nº 3, p.481-503, jul-set, 2014. 
qualidade próxima do Eta20, o que é de se esperar, uma vez que esses dois modelos utilizam sistemas de assimilação similares. Avaliando o modelo RPSAS, este apresenta valores do EMQ de $1 \mathrm{~cm}$, o modelo Eta15 apresenta EMQ de 0,4 cm e o modelo Eta20 valores variando entre $0,2 \mathrm{~cm}$ até $0,4 \mathrm{~cm}$, o que configura o melhor desempenho em relação aos outros modelos nesse mês de fevereiro.

\subsection{Avaliação Sazonal}

A Figura 4 apresenta os resultados da avaliação sazonal da qualidade do ZND nas estações selecionadas.

As previsões do ZND utilizando o modelo de PNT, apresentam EMQ de 3 à $3,5 \mathrm{~cm}$ para o mês de fevereiro nas três primeiras estações, e nas demais de $3,5 \mathrm{~cm}$ à $4,5 \mathrm{~cm}$. A variação sazonal pode ser observada com menor intensidade nas estações mais próximas ao equador (por exemplo, NAUS e BRAZ) do que as ao sul, como já discutido. No entanto, mesmo nas estações próximas do equador observa-se um impacto da variação sazonal na qualidade das previsões do ZND. Os valores do EMQ são ligeiramente menores no verão, nas estações NAUS, BRAZ, UBER, SJRP. Nas estações mais ao sul (a partir da estação PPTE) os valores do EMQ são menores no inverno do que no verão, o qual é o resultado mais preponderante nessa figura.

Figura 4 - Avaliação sazonal da qualidade do ZND (Jan e Jul de 2012) com modelo Eta15 nas estações NAUS, BRAZ, UBER, SJRP, PPTE, UFPR, PRGU e SMAR.

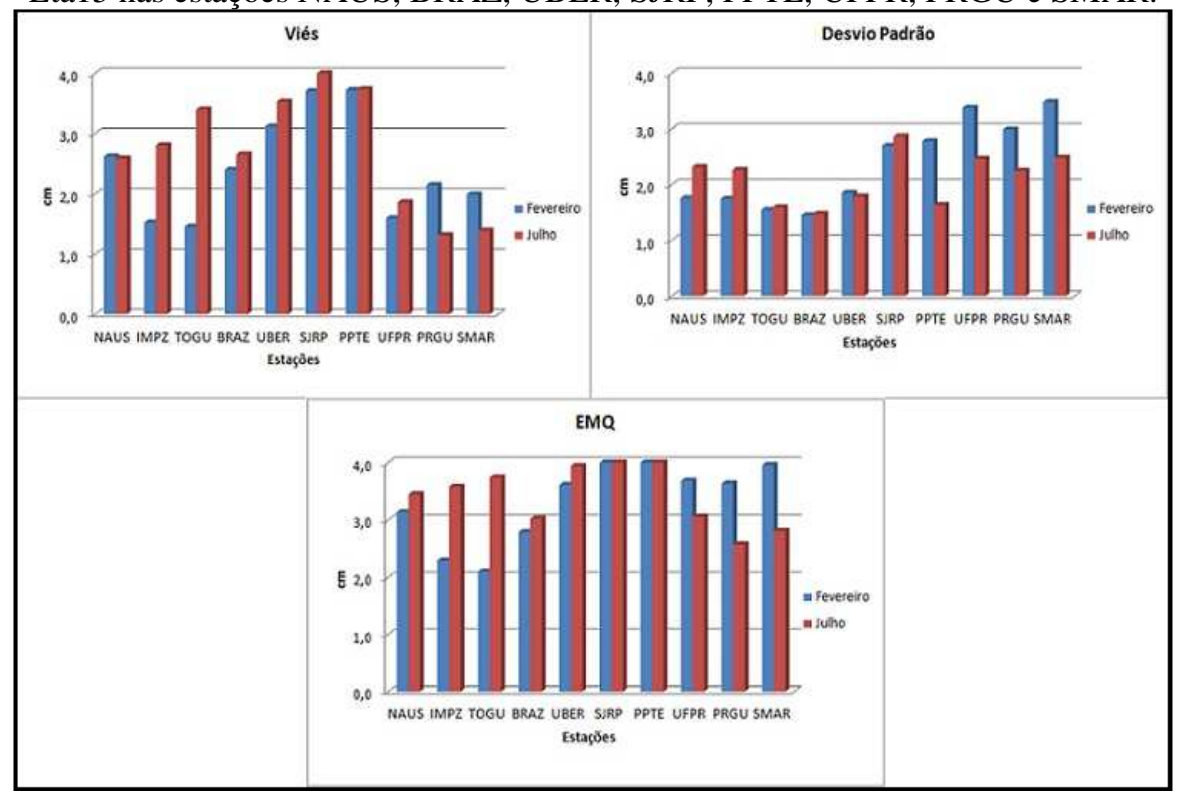

Bol. Ciênc. Geod., sec. Artigos, Curitiba, v. 20, nº 3, p.481-503, jul-set, 2014. 
A qualidade das estimativas do ZND para as regiões ao sul do Brasil é melhor no inverno do que no verão. Uma justificativa para esse resultado é o maior número de acertos do modelo de PNT em relação às previsões no inverno do que no verão, pois no inverno as chegadas das frentes frias e sua propagação sobre o continente são melhores detectadas e previstas pelo modelo. No verão, com o forte aquecimento do continente pelos raios solares, as frentes frias podem não se propagar como previsto pelo modelo. Isso é claramente observado nos valores do desvio padrão apresentados na Figura 4, onde se observa uma melhoria significativa na incerteza durante o inverno com relação ao verão.

\subsection{Continentalidade}

Os resultados gerados em relação à análise do impacto da continentalidade na qualidade das previsões do ZND são apresentados na Figura 5.

Os resultados mostrados na Figura 5 indicam que o viés apresenta-se mais variável em função das horas de integração do modelo para as estações continentais do que para as estações costeiras, especialmente para as primeiras horas de integração nas estações mais próximas do equador. Com relação ao desvio padrão ele é maior nas estações costeiras do que nas continentais em praticamente todas as horas de previsão do modelo. A combinação desses dois resultados no EMQ indica um impacto mais significativo da continentalidade nas regiões mais ao sul do Brasil (SMAR-POAL) do que nas regiões de média para baixa latitude.

Figura 5 - Avaliação da qualidade do ZND em relação à continentalidade, nos pares de estações CEEU-NAUS (a), RIOD-PPTE (b), SMAR-POAL (c), com o modelo

Eta15, em Fevereiro de 2012.

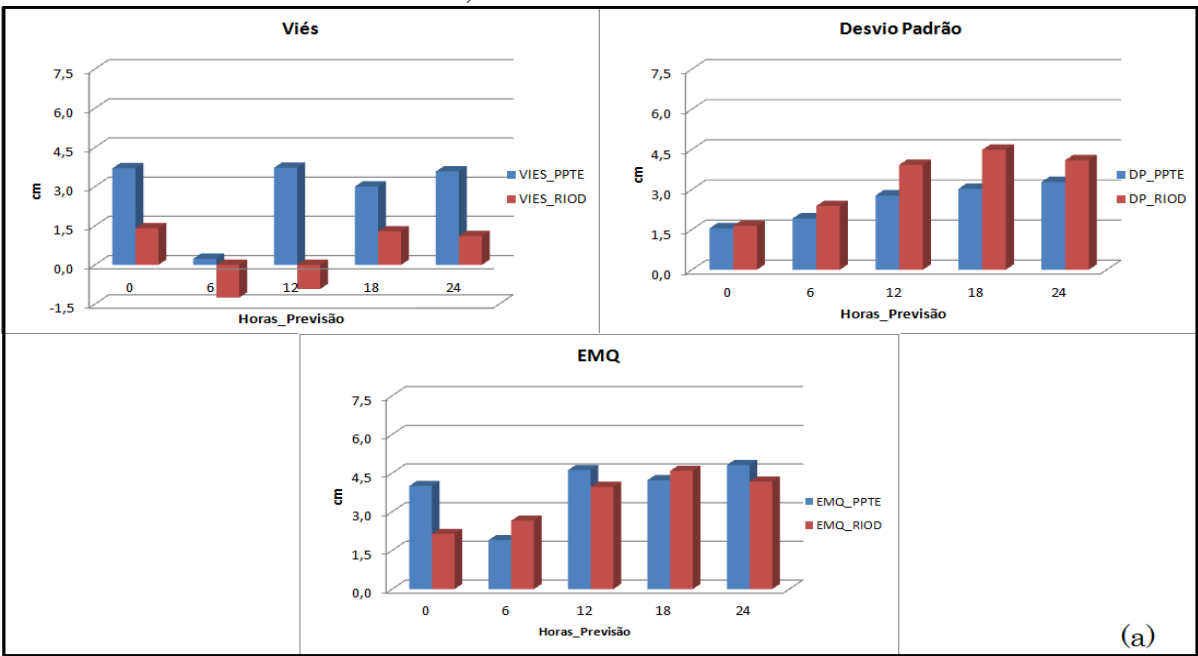

Bol. Ciênc. Geod., sec. Artigos, Curitiba, v. 20, nº 3, p.481-503, jul-set, 2014. 

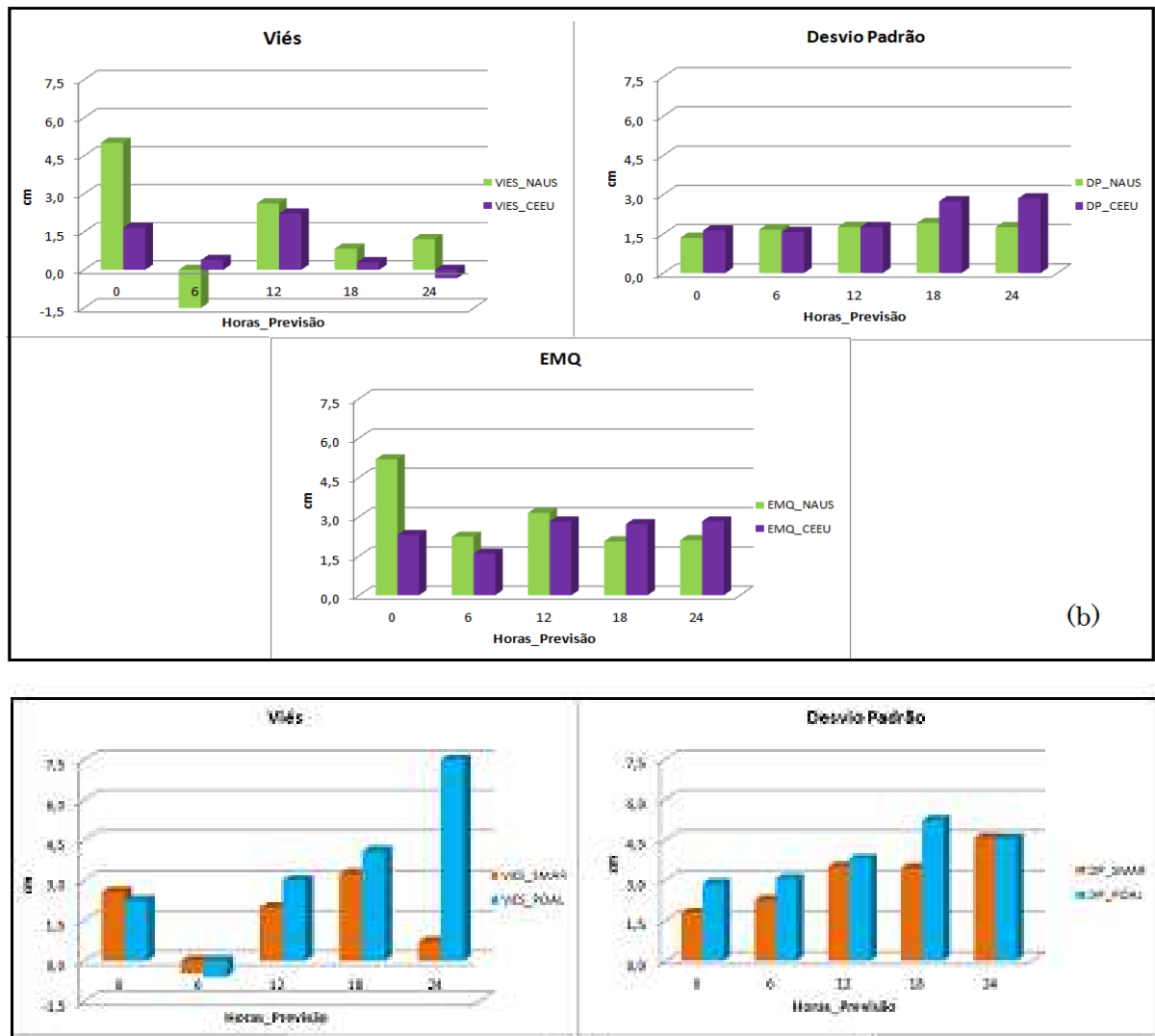

$n>$ sime

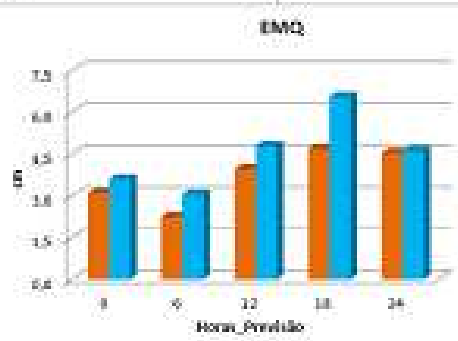

sue anv

stuserar

Enquanto nas estações NAUS-CEEU (Figura 5(a)) e PPTE-RIOD (Figura 5(b)) os resultados se confundiam durante as horas de integração do modelo, nas estações SMAR-POAL (Figura 5(c)) o EMQ na estação mais continental apresentase sistematicamente menor do que na estação litorânea. Algo que merece ser destacado é o viés acentuado na análise (condição inicial) nas estações NAUS e 
PPTE, os quais são maiores do que os observados nas estações litorâneas próximas. Esse viés acentuado impacta significativamente o EMQ nessas circunstâncias, onde o padrão destacado acima não se caracteriza claramente.

\subsection{Variação da Latitude}

Os resultados são apresentados na Figura 6, onde pode-se avaliar a taxa de variação das métricas estatísticas em função da latitude, foi ajustada uma reta nos valores apresentados na Figura 6

Figura 6 - Análise do modelo Eta15 nas previsões do ZND no mês de Fevereiro de 2012, estações litorâneas em diferentes latitudes.

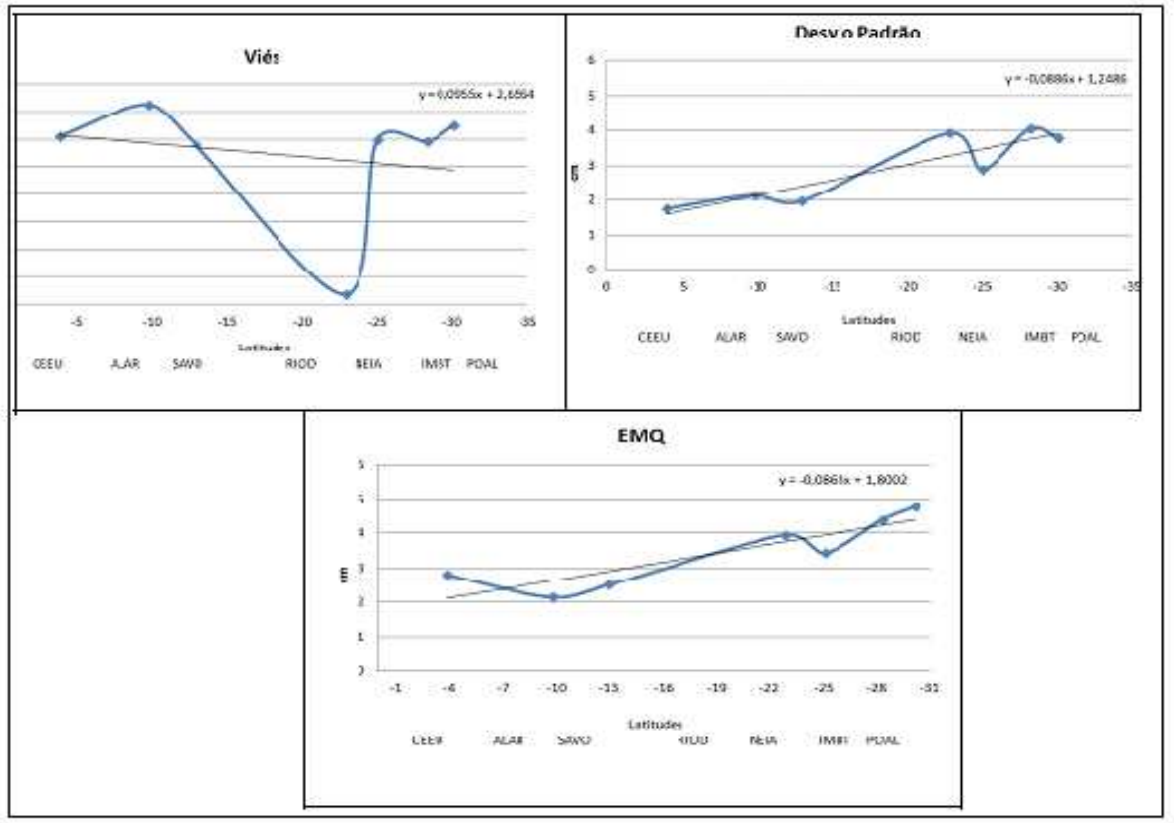

O EMQ apresentado revela que o erro do modelo aumenta de acordo com o aumento da latitude, o que pode-se observar da estação CEEU (latitude $-3,88^{\circ}$ ) onde o EMQ é de $2,1 \mathrm{~cm}$, enquanto na estação POAL (latitude $-30,07^{\circ}$ ) o valor do EMQ é de $4,2 \mathrm{~cm}$. Esse comportamento está associado com o fato de que as variações atmosféricas são menos intensas no equador do que nas regiões de latitudes médias onde há o encontro das massas de ar frio vindas do pólo sul com o continente aquecido. O coeficiente angular da curva de tendência ilustrada na Figura 6 apresenta a taxa de variação em relação ao aumento do EMQ, ou seja, a razão entre o aumento da latitude e o valor do EMQ, de $0,086 \mathrm{~cm}$, aproximadamente $1 \mathrm{~cm} \mathrm{em}$ EMQ a cada $10^{\circ}$. Esse comportamento é bem mais caracterizado no verão do que no

Bol. Ciênc. Geod., sec. Artigos, Curitiba, v. 20, nº 3, p.481-503, jul-set, 2014. 
inverno. Se a mesma análise fosse feita no inverno essa correlação da latitude com o aumento do EMQ não deve ser significativa, como indica os resultados apresentados na Figura 4. A reta de ajuste nos valores do viés indica uma diminuição do viés enquanto que o desvio padrão apresenta uma taxa semelhante àquela observada nos valores do EMQ.

\subsection{Variação da Altitude}

A Figura 7 mostra a qualidade das previsões do ZND obtido com o modelo Eta15, no mês de fevereiro de 2012.

Os resultados mostrados na Figura 7 possibilitam avaliar que não há uma relação direta dessas duas variáveis. Observam-se variações significativas entre estações relativamente próximas em altitudes. Por exemplo, o EMQ em CUIB é de 2,4 $\mathrm{cm}$ e em ROSA é de 3,9 $\mathrm{cm}$ as quais se distanciam em altitude apenas em $50 \mathrm{~m}$. No entanto, se traçar uma linha de tendência, como apresentada na Figura 7, é possível observar que ocorre um suave aumento na qualidade das previsões ZND geradas pelo modelo Eta15 com o aumento da altitude. A taxa de variação do EMQ de linha de ajuste é de $0,3 \mathrm{~mm}$ a cada $1000 \mathrm{~m}$ de variação na altitude, o que pode ser considerado desprezível.

Figura 7 - Análise da qualidade das previsões do ZND com Eta15 em função da variação da altitude usando dados do mês de Fevereiro de 2012.

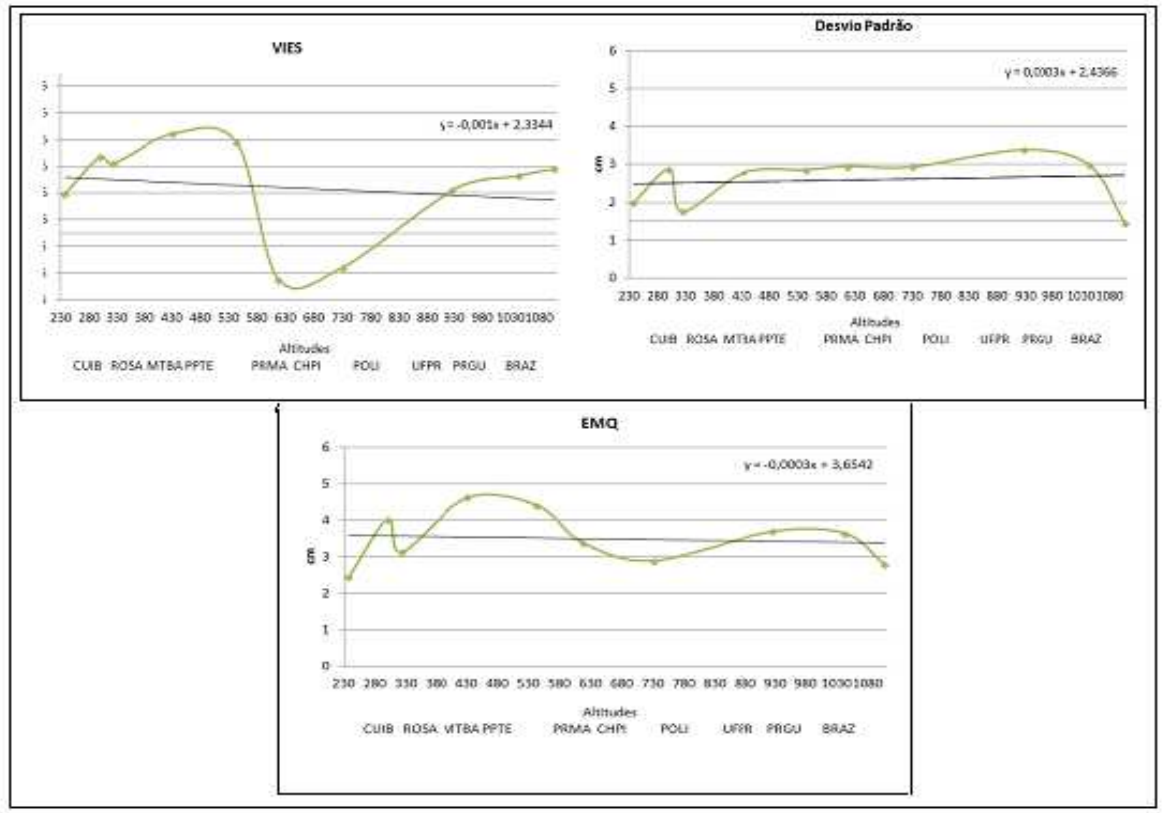

Bol. Ciênc. Geod., sec. Artigos, Curitiba, v. 20, nº 3, p.481-503, jul-set, 2014. 


\section{CONCLUSÕES E COMENTÁRIOS FINAIS}

Nesse artigo foi realizado levantamento das novas versões da modelagem do ZND usando modelos de previsão numérica de tempo, disponíveis no CPTEC, os quais apresentam melhorias na resolução espacial, temporal e adicionalmente a que utiliza melhor a base de dados coletados sobre a América do Sul. As melhorias dos modelos impactam na qualidade das previsões do ZND, que desde sua origem (2004 resolução $100 \mathrm{~km}$ em 6 horas) atualmente apresenta melhor resolução (15km e 3 horas).

Uma avaliação robusta levando em consideração 77 estações da RBMC e os meses de janeiro, fevereiro, abril, julho e outubro (estações do ano) de 3 anos de dados é apresentada, na qual, diversos aspectos são avaliados. Na análise robusta, o EMQ do Eta20 e do RPSAS foi de 2,5 cm, enquanto que o Eta15 na avaliação feita em 2012 apresentou um EMQ de 5,5 cm, sendo que o viés foi praticamente nulo em todos os períodos avaliados. O Eta20 apresentou desempenho superior aos demais modelos, até em relação ao Eta15, de aproximadamente $0,2 \mathrm{~cm}$.

$\mathrm{Na}$ avaliação do impacto da variação sazonal na qualidade das previsões do ZND, os resultados mostram que ela é mais significativa nas estações abaixo de $20^{\circ} \mathrm{S}$ de latitude, nas quais o EMQ do ZND é menor durante o período de inverno do que no verão, cuja diferença pode chegar até $1 \mathrm{~cm}$ no EMQ (valor observado na estação SMAR). Já nas estações mais ao norte esse aspecto não impacta significativamente os resultados. Essa modificação no EMQ é causada mais proeminentemente pela diminuição do desvio padrão do que do viés. As incertezas do modelo são minimizadas durante o inverno em regiões temperadas, período no qual se torna mais fácil prever os fenômenos atmosféricos de grande escala.

$\mathrm{Na}$ avaliação da qualidade do ZND em relação à continentalidade, observou-se que a diferença no EMQ entre estações costeiras e continentais é mais significativa em regiões ao sul do Brasil (SMAR e POAL), do que nas estações de média para baixa latitude. A estação de SMAR apresentou um EMQ menor que a estação de POAL. Em relação à avaliação considerando a variação de latitude pode-se observar que o erro do modelo sofre um aumento de acordo com o aumento da latitude. Isso não é observado com a variação da altitude, onde a diminuição do EMQ em função da altitude foi irrisória, apresentando suave aumento na qualidade das previsões ZND geradas pelo modelo Eta15 com o aumento da altitude. Maiores detalhes e resultados desenvolvidos são apresentados em Gouveia (2013).

Os resultados mostraram que a versão Eta20 apresentou melhores resultados do que a versão atualmente operacional. No processo de substituição das versões do Eta20 para Eta15 não houve apenas modificação na resolução, mas por problemas de engenharia de software com o novo supercomputador a versão teve que sofrer modificações mais drásticas e em alguns pontos menos rigorosas, de tal forma que não houveram ganhos significativos em qualidade nas previsões. Com o objetivo de amenizar esse problema encontra-se em avaliação uma versão com a assimilação de dados. O melhor resultado que a versão com assimilação de dados aqui avaliada apresentou foi à estabilização da qualidade ao longo das previsões no dia e ao longo

Bol. Ciênc. Geod., sec. Artigos, Curitiba, v. 20, nº 3, p.481-503, jul-set, 2014. 
dos meses de 2010 e 2011, enquanto o modelo Eta20 apresenta degradação da qualidade em relação aos anos de 2010 e 2011. Como é apresentado em Herdies et al. (2008) até 48 horas de previsão o modelo de assimilação regional RPSAS não perde a qualidade, o que já não ocorre com os demais modelos apresentados nesse trabalho, sendo uma contribuição importante da assimilação de dados. Desde janeiro de 2013 se encontra em implantação o novo sistema de assimilação de dados G3DVar (Global 3 Dimensional Variational Assimilation - Assimilação Variacional em 3 Dimensões) com rodadas a cada 6 horas, gerando internamente dados com resolução temporal horária, e estando acoplado ao modelo de previsão do CPTEC/INPE denominado MCGA (Modelo de Circulação Geral e Atmosférico). O G3DVar mesmo sendo global, apresenta a mesma resolução espacial que o RPSAS, porém utiliza uma quantidade de dados muito maior do que esse com a inclusão de novos sistemas de observação. Entre esses sistemas de observação encontra-se as estimativas do vapor d'água atmosférico obtidas através de dados GNSS coletados pela RBMC. Baseado nos tópicos apresentados acima, essa versão apresenta um forte potencial para contribuir com a melhoria da qualidade da atual versão das previsões do ZND o que permitirá novas promissoras pesquisas. Para análise do impacto dessas melhorias nas previsões do $\mathrm{ZND}$, novos trabalhos estão em desenvolvimentos no CPTEC em colaboração com a UNESP, como atividades futuras dessa linha de pesquisa, e consequentemente novas versões das previsões do ZND deverão ser disponibilizadas.

\section{AGRADECIMENTOS:}

Os autores agradecem aos colaboradores da Divisão de Satélites e Sistema Ambientais e do Grupo de Desenvolvimento em Assimilação de Dados da Divisão de Desenvolvimento e Modelagem do CPTEC-INPE que direta ou indiretamente contribuíram com essa pesquisa. Agradecimentos são também devidos a CAPES pela bolsa de auxílio e a FAPESP (Processo N. 2006/04008-2 e Processo 2012/19906-7), CNPq (Processo 477947/2010-7) e ao Instrumento Contratual da Rede Temática de Estudos Geotectônicos CT-PETRO (PETROBRAS) e o INPE (processo número 4600289299) pelo apoio a essa pesquisa.

\section{REFERÊNCIAS BIBLIOGRÁFICAS}

ANDREOLI, R. V.; HERDIES, D. L.; SOUZA, R. A. F.; SAPUCCI, L. F.; ARAVÉQUIA, J. A.; FERREIRA, S. H. Tipos de observações e o controle de qualidade utilizado na assimilação de dados no CPTEC/INPE. Instituto Nacional de Pesquisas Espaciais - INPE, v.1, 2008.

BEVIS, M. G.; SUSINGER, S.; HERRING, T.; ROCKEN, C.; ANTHES, R. A.; WARE, R. H. GPS Meteorology: Remote of Atmospheric Water Vapor Using the Global Positioning System. Journal of Geophysical Research, v. 9, p. 15.787 - 15.801, 1992. 
BLEWITT, G. Advances in Global Positioning System Technology for Geodynamics Investigations: 1978-1992 in An Introduction to GIPSY/OASISII.JPL 4800 Oak Grove Drive, Pasadena, CA 91109, 1997.

CAMARGO, P. O. Modelo Regional da Ionosfera Para uso em Posicionamento com Receptores GPS de uma Freqüência. 1999. 191f. Tese (Doutorado em Ciências Geodésicas) - Universidade Federal do Paraná, Curitiba.

DALBELO, L. F. A; ALVES, D. B. M; MONICO, J. F. G.; SAPUCCI, L. F. Minimizando o atraso zenital troposférico no posicionamento DGPS: comparação da modelagem dinâmica com o modelo de Hopfield. Simpósio Brasileiro de Geofísica Espacial e Aeronomia - SBGEA, 2006. São José dos Campos - SP.

GOUVEIA, T. A. F. Modelagem neutrosférica sobre a América do Sul baseada em PNT e assimilação de dados locais e robusta avaliação utilizando observações GNSS. 2013. 136 f. Dissertação (Mestrado em Ciências Cartográficas) Faculdade de Ciências e Tecnologia, Universidade Estadual Paulista, Presidente Prudente.

GREGORIUS T. How it Works...GIPSY-OASIS II. Department of Geomatics. University of Newcastle upon. Tyne, Canadá, 1996.

HERDIES, D. L.; ARAVEQUIA, J. A.; FERREIRA, S. H. S.; SOUZA, R. V. A.; SAPUCCI, L. F.; MATTOS, J. G. F. A Assimilação de Dados no CPTEC/INPE. Boletim da Sociedade Brasileira de Meteorologia, v. 32, p. 5764, 2008.

MONICO, J. F. G.; DAL PÓZ, A. P.; GALO, M.; SANTOS, M.C.; OLIVEIRA, L. C. Acurácia e precisão: Revendo os conceitos de forma acurada. Boletim de Ciências Geodésicas, v. 15, n.3, 2009.

MONICO, J. F. G. Posicionamento pelo GNSS: Descrição, Fundamentos e Aplicações. 2.ed. São Paulo: UNESP, 2008. 480p.

OLIVEIRA, A. F. Análise de Modelos Troposféricos no posicionamento baseado em Redes Usando o Conceito de VRS. Boletim de Ciências Geodésicas, v. 20, n.1, 2014.

SAPUCCI, L. F.; MONICO, J. F. G.; MACHADO, L. A. T.; ROSA, G. P. S. Avaliação das Previsões do Atraso Zenital Troposférico para a América do Sul Obtidas Usando Modelo de Previsão Numérica de Tempo com Alta Resolução Espacial. Boletim de Ciências Geodésicas, v.14, n.4, 2008.

SAPUCCI, L. F.; MONICO, J. F. G.; MACHADO, L. A. T.; HERDIES, D. L.; SOUZA, R. A. F. Assimilação do IWV-GPS no Brasil: Otimização das estimativas do atraso zenital troposférico em tempo real. Revista Brasileira de Geofísica, v. 25, p. 1000, 2007.

SAPUCCI, L. F.; MACHADO, L. A. T; MONICO, J. F. Galera. Previsões do Atraso Zenital Troposférico para a América do Sul: Variabilidade Sazonal e Avaliação da Qualidade. Revista Brasileira de Cartografia, v. 58, p. 279-292, 2006. 
SAPUCCI, L. F. Estimativas do IWV utilizando receptores GPS em bases terrestres no Brasil: Sinergia entre a Geodésia e a Meteorologia. 2005. 200 f. Tese (Doutorado em Ciências Cartográficas) - Faculdade de Ciências e Tecnologia, Universidade Estadual Paulista, Presidente Prudente.

SAPUCCI, L. F.; MACHADO, L. A. T.; MONICO, J. F. G. Modelagem dinâmica do atraso zenital troposférico para America do Sul empregando previsão numérica de tempo. In: I SIMGEO, 2004. Recife. Anais I SIMGEO, 2004.

SAPUCCI, L. F. Estimativa do vapor d'água atmosférico e avaliação da modelagem do atraso zenital troposférico utilizando GPS. 2001. $167 \mathrm{f}$. Dissertação (Mestrado em Ciências Cartográficas) - Faculdade de Ciências e Tecnologia, Universidade Estadual Paulista, Presidente Prudente.

SEEBER, G. Satellite geodesy: foundations, methods, and application. Berlin, New York: Walter de Gruyter, 2003. 589p.

SPILKER,J.; J. JR. Tropospheric Effects on GPS. In: PARKINSON, B. W.; SPILKER Jr., J. J. Global Positioning System: Theory and Applications. Cambridge: American Institute of Aeronautics and Astronautics, 1996. v.1, p.517-546.

(Recebido em outubro de 2013. Aceito em Fevereiro de 2014). 